\title{
Ética e formação: o elogio ao processo argumentativo
}

Antônio A. S. Zuin

Professor da Universidade Federal de São Carlos

Belarmino César Guimarães da Costa

Professor da Universidade Metodista de Piracicaba

\section{Resumo}

Em tempos de cultura digital, observa-se o acesso a uma quantidade incomensurável de informações sem que sejam feitas relações que poderiam transformá-las em conceitos. Uma vez que prevalece o uso instrumental de tais informações, arrefece concomitantemente a postura ética que o questiona. É nesse contexto que o professor ocupa um posto decisivo no que diz respeito à organização e à discussão de tais informações com seus alunos. Esse artigo tem como objetivo argumentar que a postura de Pedro Goergen como educador oferta aos alunos um tipo de relação que faz com que a própria figura do professor seja eticamente ressignificada, nessa sociedade de cultura digital.

Palavras-chave: Pedro Goergen; Ética; Formação.

\begin{abstract}
In times of digital culture, one can note the access to an immeasurable amount of information without establishing relations which could convert them into concepts. Since the prevailing instrumental use of such information, there is a decline of the ethical stance that question this kind of use. It is in this context that the teacher occupies a key position with regard to the organization and discussion of such information with your students. This article aims to argue that Pedro Goergen's posture as educator offers to students a kind of relationship that makes the teacher figure itself receives ethically a new meaning, in this digital culture society.
\end{abstract}

Keywords: Pedro Goergen; Ethic; Formation.

Filosofia e Educação [RFE] - Volume 8, Número 2 - Campinas, SP
Junho-Setembro de 2016 - ISSN 1984-9605 - p. 62-78




\section{Introdução}

Mlvez nunca a profissão de ensinar tenha sido tão questionada
quanto nos dias atuais. Historicamente, sempre pairou sobre a
imagem do professor uma gama de representações aversivas que o acompanharam, até mesmo quando não mais se permitiu que castigos físicos fossem aplicados nos alunos considerados indisciplinados. De fato, se, por um lado o professor teve sua imagem consubstanciada à esfera do espírito e, por isso, muitas vezes invejada por aqueles que estavam dela excluídos, por outro lado o professor também foi objeto de contestação e de projeção de ressentimento, sobretudo pela vinculação de sua imagem com a do carrasco que pune crianças incapazes de se defender. Se tal contradição acompanha há muito a profissão de ensinar, já nos dias atuais a figura do professor parece tornar-se tão descartável quanto um produto qualquer, passível de ser substituído sem muitos pruridos.

A descartabilidade do professor pode ser observada sob os mais variados prismas: ela está presente no professor que não suporta as péssimas condições de trabalho relacionadas a salários aviltantes, a jornadas de trabalho estafantes, à violência física e simbólica entre os alunos e contra os próprios professores, ou então no professor que é demitido das escolas particulares por não ter sido de total agrado para seus alunos clientes. Não por acaso, atualmente há várias propagandas da televisão que tentam valorizar a figura do professor de forma explícita. Contudo, se tais propagandas são cada vez mais constantes, é porque também há muito tempo o professor já não possui a valorização que tentam lhe atribuir. $\mathrm{E}$ mais: muitas vezes justificam-se, ideologicamente, todos os problemas acima listados como um fardo que o professor tem de tolerar porque possui

\begin{tabular}{l}
\hline Filosofia e Educação [RFE] - Volume 8, Número 2 - Campinas, SP \\
Junho-Setembro de 2016 - ISSN 1984-9605 - p. 62-78
\end{tabular}


uma espécie de vocação, de uma essência professoral que deveria fazer com que aceitasse de bom grado a supostas mazelas de seu destino.

Mas é justamente em tempos como esses que é preciso enfatizar a relevância do papel do professor. Sobretudo nos tempos da chamada cultura digital, na qual prevalece o paradoxo de se ter acesso a uma quantidade incomensurável de informações sem que sejam feitas relações que poderiam tensioná-las, a ponto de se transformarem em conceitos. Mais do nunca, o professor ocupa um posto decisivo no que diz respeito à organização e discussão de tais informações com seus alunos.

A partir da epígrafe - quando Adorno (1995, p. 132-133) assinala que a fetichização da técnica identifica uma anomalia societária que responde pela separação entre o objeto e a autoconservação, fazendo com que o suporte se desprenda da condição de extensão humana e seja algo em si mesmo -, torna-se emblemático identificar traços da racionalidade técnica e da antítese informação circulante e experiência. Na cultura digital, que é caracterizada pela ampliação da capacidade de armazenagem, distribuição e acesso de conteúdos, associada à mobilidade de equipamentos e conexão sistêmica, as relações humanas, entre culturas e processos civilizatórios se dão de forma mediada pela tecnologia, com rupturas de temporalidade e de espacialidade. O fascínio tecnológico demarcado pela composição imagética da computação gráfica, games e animações, tornando diluídas as fronteiras entre realidade e imaginário, linguagem informacional, entretenimento e publicidade, requer intervenção de projetos educativos que ampliem a compreensão dos mecanismos que geram opacidade em meio à aparente ilustração conferida pelos produtos da indústria cultural, cada vez mais atraentes em seus formatos e linguagens.

Nesse sentido, a educação para compreensão do caráter fetichista da técnica e sua ocultação na reprodução digital dos objetos da indústria 
cultural, ainda mais com a desmaterialização e a conectividade das plataformas, sugere apreensão dos elementos estéticos e não meramente afetos aos enunciados; daí a importância da mediação do professor para refletir sobre as dimensões civilizatórias, filosóficas e políticas dos componentes técnicos. Possibilidades de intervenção e de interpretação dos fenômenos afetos à digitalização e à ação da indústria cultural contemporânea decorrem, em grande medida, das pesquisas interdisciplinares e do encantamento de professores que cultivam a autonomia do educando.

Este artigo tem como objetivo argumentar que a postura de Pedro Goergen como educador oferta aos seus alunos um tipo de modelo que porta consigo características centrais para que a própria figura do professor possa ser ressignificada, principalmente na sociedade da denominada cultura digital. Porém, antes de argumentar nessa direção, faz-se necessário refletir sobre o significado do papel do professor, bem como a história das representações aversivas que pairam sobre a sua própria profissão.

\section{A história dos tabus referentes à imagem do professor}

Quando se trata de discutir a imagem do professor, é inevitável a lembrança das ponderações de Theodor W. Adorno sobre essa questão, as quais estão presentes no seu texto: "Tabus a respeito do professor" (ADORNO, 2012). Com efeito, ele define os tabus em relação aos professores como:

representações inconscientes ou pré-conscientes dos que se candidatam a essa profissão (a de ensinar) - mas também dos demais, em especial das próprias crianças - que se impõem como uma espécie de interdição psíquica a essa profissão e que the levantam dificuldades, das quais raramente se alcança uma ideia 
clara. Portanto, emprego o conceito de tabu num sentido mais rigoroso como a sedimentação coletiva de representações que, de maneira similar às de caráter econômico que mencionei, perderam sua base em grande medida mas que, como preconceitos sociais e psicológicos, persistem teimosamente e, por sua vez, tornam-se forças atuantes na realidade, tornam-se forças reais (ADORNO, 2000, p.158-159).

De acordo com a linha de raciocínio desenvolvida por Adorno, mesmo com a passagem do tempo e, portanto, mesmo com as transformações históricas que ocorreram nas relações estabelecidas entre professores e alunos, ainda permanece presente uma espécie de interdição psíquica em relação à profissão de ensinar. Mas, se tal interdição psíquica permanece com o passar do tempo, é necessário compreender as diferentes formas pelas quais tais interdições são sedimentadas em determinadas representações coletivas.

Assim, na Atenas do $\mathrm{V}$ século antes de Cristo, o aluno tinha um escravo como primeiro educador. Pois vários guerreiros que foram derrotados nos campos de batalha transformaram-se em escravos que eram identificados como paedagogus, ou seja, os responsáveis por controlar e guiar o rapaz até as escolas (CAMBI, 1999, p. 84). Manacorda destaca na Roma antiga uma frase de Sêneca, o retor, que, ao se referir aos escravos pedagogos, sentenciou: "era vergonhoso ensinar o que era honroso aprender" (Manacorda, 1989, p.78). Ou seja, havia honra no aprendizado dos conteúdos de Matemática ou da língua vernácula, mas não se podia evitar o sentimento de vergonha, pois era um escravo que se responsabilizava pelos primeiros ensinamentos que formariam o futuro cidadão romano.

\begin{tabular}{l}
\hline \hline Filosofia e Educação [RFE] - Volume 8, Número 2-Campinas, SP \\
Junho-Setembro de 2016 - ISSN 1984-9605 - p. 62-78
\end{tabular}


Para que os alunos se concentrassem nos estudos dos conteúdos das matérias, não era raro que o professor utilizasse o castigo físico como recurso para controlar a disciplina. Há várias pinturas em vasos e outros artefatos de cerâmica, tais como as que são hoje exibidas no museu de arqueologia nacional de Nápoles, nas quais os alunos têm os braços e as pernas imobilizados por outros colegas, ao mesmo tempo em que um professor os açoita com um chicote (LEGRAS, 2008, p. 25).

É difícil precisar o momento histórico que marcou a proibição dos castigos físicos aplicados pelos professores em seus alunos, pois há mediações históricas específicas relacionadas aos sistemas de ensino locais. Contudo, na história da pedagogia há uma obra que se destaca ante as demais quanto ao tema da aplicação de tais castigos físicos: trata-se da Didactica Magna: tratado da arte universal de ensinar tudo a todos, de Comênio. Ao criticar o emprego dos castigos físicos durante o transcorrer das relações estabelecidas entre os professores e alunos nas salas de aula, Comênio observa o seguinte:

Se, porém, por vezes, é necessário espevitar e estimular, o efeito pode ser obtido por meio de outros meios e melhores que as pancadas: às vezes, com uma palavra mais áspera e com uma repreensão dada em público; outras vezes, elogiando os outros: "Olha como estão atentos este teu colega e aquele, e como entendem bem todas as coisas! Porque é que tu és assim tão preguiçoso?"; outras vezes suscitando o riso: "Então tu não entendes uma coisa tão fácil? Andas com o espírito a passear?" Podem ainda estabelecer-se "desafios" ou "sabatinas" semanais, ou ainda mensais, para ver a quem cabe o primeiro lugar ou a honra de um elogio, $[\ldots]$ desde que se veja que isto não vai resultar num mero divertimento ou numa brincadeira, e por isso inútil, mas para 
que o desejo do elogio e o medo do vitupério e da humilhação estimulem verdadeiramente à aplicação. (COMÊNIO, 1985, p. 403).

Não por acaso, essas considerações de Comênio estão presentes no capítulo "Da disciplina escolar", de sua Didactica Magna. Trata-se de uma reviravolta no trato das questões disciplinares, na medida em que as punições psicológicas gradativamente começam a erigir sua supremacia sobre as punições de ordem física. A frase: "Então tu não entendes uma coisa tão fácil? Andas com o espírito a passear?" pode não engendrar a dor que uma pancada produz na palma da mão do aluno, mas seus efeitos dolorosos podem, por outro lado, ser muito mais duradouros, pois dificilmente a humilhação que o aluno sentiu por ser assim destacado diante de seus colegas irá dissipar-se tão facilmente. Aliás, Comênio tinha plena consciência em relação ao uso de uma espécie de reforço negativo do comportamento do aluno, para utilizar um conceito de Skinner, no sentido de se evitar o reaparecimento de determinado comportamento indesejável, mediante a distinção humilhante de um aluno diante dos demais. Era imprescindível fazer com que o "desejo do elogio e o medo do vitupério e da humilhação" fomentassem nos alunos a intenção de comportar-se de acordo com as normas estabelecidas pelo professor.

De forma geral, o professor sempre foi identificado como o modelo a ser seguido, embora pairasse sobre si as representações aversivas anteriormente destacadas. É que não se pode evitar a constatação de que o professor, de uma forma ou de outra, ocupou o posto de objeto de projeção de sentimentos ambivalentes por parte dos alunos. Pois os alunos tanto o odiavam quanto o amavam, de tal maneira que o professor representou, historicamente, uma espécie de substituto do pai (Freud, 1969).

\begin{tabular}{c}
\hline \hline Filosofia e Educação [RFE] - Volume 8, Número 2 - Campinas, SP \\
Junho-Setembro de 2016 - ISSN 1984-9605 - p. 62-78
\end{tabular}


Johann Friedrich Herbart, um dos principais representantes da denominada pedagogia humanista tradicional, asseverou que era o professor que detinha o poder de, por meio do exercício de sua autoridade, antecipar aos alunos os "objetivos do homem futuro" (Herbart, 2003, p. 43). Para que o aluno internalizasse a disciplina a ponto de considerá-la um aspecto fulcral para o próprio desenvolvimento de suas capacidades cognitivas e afetivas, seria fundamental a presença do professor. O mestre apresentaria a importância de que, por meio da razão, o aluno soubesse escolher as melhores opções para si e para a coletividade a que porventura pertencesse. Pois se assim procedesse seria identificado como um aluno de caráter. Porém, tal internalização não seria uma espécie de caminho suave, uma vez que vários obstáculos internos e externos deveriam ser transpostos. Há uma consideração de Herbart que ilustra muito bem o papel do professor diante das dificuldades de aprendizado e de disciplina experimentadas pelos alunos:

A disciplina não deve tocar erradamente a alma [...]. O educando não se lhe deve opor interiormente de modo nenhum, nem moverse em diagonal como impelido por duas forças. Mas donde receber uma receptividade aberta e límpida, se não da crença da criança na força e intenção benéfica do educador? E como poderia um comportamento frio, estranho e de repulsa, conduzir a essa crença? - A disciplina só tem razão de ser na medida em que uma experiência interior aconselha aquele que lhe está submetido a suportá-la com agrado (HERBART, 2003, p. 186).

Decididamente, para Herbart o professor deve ser um modelo para o aluno, na medida em que ele deve "afirmar a superioridade sobre as crianças de um modo que torne sensível uma força formativa" (Herbart, 2003, p.

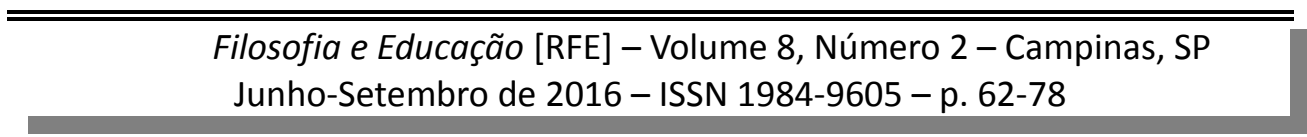


188). Para que houvesse tal afirmação da superioridade do professor, Herbart enfatiza a necessidade de que certas fronteiras fossem estabelecidas entre professores e alunos. Assim, o professor que descesse ao nível dos alunos não perceberia os

novos e inúmeros erros que com isso se cometem! Ignora-se que se exige o que não deve ser, algo que a natureza inevitavelmente penaliza, porque está a pretender-se que um adulto desça ao nível da criança e, desse modo, construa um mundo infantil (HERBART, 2003, p. 20).

Já Rousseau (1712-1778), um dos principais representantes da chamada pedagogia humanista moderna, defendeu veementemente que "se eles [os alunos] não puderem ainda erguer-se até vós, descei a eles sem vergonha, sem escrúpulo" (ROUSSEAU, 1992, p. 280). Para que Emílio, seu aluno fictício, aprendesse, por meio do uso da razão, a equilibrar as relações de tensão entre a realização de seus desejos e a obediência às leis dos contratos sociais, o professor, de acordo com Rousseau, deveria comunicar-se sem escrúpulos com ele, de modo a se colocar no lugar dele para que pudesse efetivamente compreender suas dificuldades e exaltar seus progressos. Embora houvesse tal diferença entre Herbart e Rousseau sobre o papel do professor no trato pedagógico com seus alunos, não se pode desconsiderar o fato de que ambos realçaram a importância dele no desenvolvimento das relações estabelecidas com o alunado. Já atualmente, na sociedade da chamada cultura digital, o professor parece cada vez mais deixar de exercer tal importância. 


\section{A docência na cultura digital:}

\section{Pedro Goergen como exemplo de contrafogo}

Na sociedade da chamada cultura digital, o computador possibilita

a realização de encontros sociais e particulares, processamento e transmissão de dados, a elaboração de atividades de trabalho e de diversão, televisão e comunicação, concentração e dispersão, ser ignorado ou ser percebido, a ponto de todas essas potencialidades se tornarem indiscerníveis entre si (TÜRCKE, 2010, p. 44).

Nessa sociedade, há quem diga que as escolas não serão mais necessárias em pouco tempo. Diante da facilidade de acesso às mais variadas informações, não seria mais necessária a existência da escola como instituição, pois seus participantes produziriam e disseminariam conhecimento exclusivamente por meio das novas tecnologias de comunicação e informação. Essa posição açodada revela muito sobre o modo como o professor deixa de ser considerado um participante relevante no processo de ensino e aprendizagem. Evidentemente, os docentes reagem em relação ao seu próprio, por assim dizer, esvaziamento. E tal reação é caracterizada, em muitas ocasiões, como violenta e não menos apressada. No ano de 2011, uma aluna adolescente que frequentava uma tradicional escola carioca criou um blog para que pudesse trocar informações sobre os professores e suas matérias com outros alunos. Quando a direção da escola soube de tal iniciativa, emitiu a seguinte nota:

"A instituição tomou as medidas cabíveis, seguindo sua linha pedagógica, ao constatar que a aluna administrava página na rede social na qual usava o logo da instituição e veiculava material 
didático do colégio sem autorização e de forma inadequada" (MENCHEN, 2011, p. 11).

Assim, os gestores educacionais optaram pela exclusão do diálogo pedagógico e pela aplicação de práticas punitivas, tais como a suspensão da aluna das atividades escolares e a ameaça de processo judicial para os pais da adolescente. Ao observar as potencialidades dos atuais recursos científico-tecnológicos e dos meios de comunicação de massa, Pedro Goergen afirma que "essas possibilidades geram uma preocupação ética de dimensões talvez nunca antes registradas nos mais diferentes domínios do conhecimento e das atividades humanas" (GOERGEN, 2011, p. 94). Mais à frente de seu texto, Goergen enfatiza a importância da existência de um processo argumentativo relacionado ao que denomina giro pedagógico:

É em função da natureza desse giro pedagógico que o vingar de novos valores, capaz de orientar a ação dos homens, depende essencialmente de um processo pedagógico de argumentação e convencimento que não representa apenas uma nova forma de impor valores, mas um processo de instituí-los e validá-los. A adesão a valores liga-se intrinsecamente ao processo democrático/argumentativo de sua instituição e fundamentação. Não se trata mais de disciplinar, de impor valores e sentidos mediante ameaças e castigos, mas de convencer os educandos, através de argumentos racionais, da importância e da necessidade de certos princípios orientadores como consensos reguladores da vida do homem em sociedade (GOERGEN, 2001, p. 123-124).

Para que ocorra esse convencimento, no caso dos contratos pedagógicos estabelecidos entre professores e alunos, os alunos precisam se sentir partícipes na elaboração e na consolidação das regras contratuais. 
Mas, para que isso ocorra, o professor precisa estimular tal participação e não solapá-la. Seguindo o exemplo da melhor tradição socrático-formativa, pode-se asseverar que as atitudes como educador do professor Pedro Goergen sempre se pautaram por tal incentivo a seus alunos.

$\mathrm{Na}$ discussão coletiva dos textos escolhidos para debater com seus orientandos de mestrado e doutorado, o prof. Pedro sempre os estimulou a desenvolver o próprio raciocínio, muitas vezes provocando a reação de tais alunos por meio de questões que tencionavam os conceitos estudados. Nesse sentido, sua prática como educador sempre se revelou consoante com seus escritos, particularmente aqueles que concerniam aos seus estudos sobre ética.

A ironia do prof. Pedro não pode ser confundida com sarcasmo, que etimologicamente significa dilacerar carne. Pelo contrário, a ironia goergiana sempre açulou o aluno a refletir sobre os conceitos que estavam sendo investigados. Ao proceder dessa forma o prof. Pedro sempre respeitou seus alunos, assim como foi respeitado por eles.

$\mathrm{Na}$ condição de orientandos ${ }^{1}$, pudemos efetivamente experimentar o significado que Pedro Goergen atribuiu e atribui ao conceito de processo argumentativo. Talvez fosse mais fácil simplesmente dizer que, como professor, ele sempre teria a prerrogativa de afirmar, indireta ou diretamente, que seria o proprietário da verdade nas conclusões elaboradas no decorrer das discussões. Talvez até mesmo fosse mais cômodo exercer tal postura autoritária, mas isso jamais ocorreu, de tal modo que nós educandos pudemos perceber o real significado do professor que se preocupa em aproximar os conteúdos que constrói em seus textos com sua própria prática

1 Tempos de memórias afetivas, leituras e debates na Faculdade de Educação da Unicamp que culminaram com os livros-teses: Indústria Cultural e Educação: O Novo Canto da Sereia (Zuin, 1999); Estética da Violência, Jornalismo e Produção de Sentidos (Costa, 2002).

\begin{tabular}{l}
\hline Filosofia e Educação [RFE] - Volume 8, Número 2 - Campinas, SP \\
Junho-Setembro de 2016 - ISSN 1984-9605 - p. $62-78$
\end{tabular}


pedagógica. Seguindo essa linha de raciocínio, o próprio exemplo de educador, apresentado e vivido por Pedro, auxilia-nos a compreender a ressignificação do modelo de ser professor na sociedade que parece cada vez mais descartá-lo. Em tempos nos quais a capacidade de concentração cada vez mais se pulveriza, em decorrência do bombardeamento audiovisual a que os indivíduos são submetidos, torna-se decisivo o papel do professor como fomentador do processo argumentativo com seus alunos. É nessa condição que o professor pode e deve assumir a tarefa de exercer um papel de contrafogo, para fazer uso da bela metáfora apresentada por Bourdieu (1998). Ou seja, diante do incêndio que tais estímulos audiovisuais provocam, o professor pode agir como uma espécie de contrafogo ao utilizar esses mesmos recursos tecnológicos para incentivar o desenvolvimento de relações dialógicas com seus alunos. Tendo por base tal premissa, Goergen argumenta o seguinte:

Há indícios de que o sujeito não se aquieta com o papel de imagem espetacular da lógica sistêmica midiático-mercantil, não se conforma com a condição de mero escravo e repetidor da ordem social neoliberal. A fragilização inicial do indivíduo, decorrente do enfraquecimento do poder regulador e orientador das instituições coletivas como a religião, o Estado, os partidos e a família, parece agora se converter em seu fortalecimento, mas em outra pauta. As novas esperanças, permito-me repetir, não residem no passado, embora este seja o fundamento de qualquer projeto futuro, nem nas utopias descoladas do presente, mas, devem emergir da hybris do presente (GOERGEN, 2011, p. 121). 
Certamente, o professor Pedro Goergen nos oferta, por meio de sua conduta ética, um exemplo vivo do educador que, kantianamente, não se conforma com tal fragilização do indivíduo e não desiste de ousar saber.

\section{Conclusão}

Kant, em seu livro Sobre a Pedagogia, destacou em termos pedagógicos um dos principais dilemas dos educadores do Iluminismo europeu: de que modo eles poderiam incitar o exercício da liberdade entre seus alunos em meio ao constrangimento da obediência das leis vigentes nas instituições escolares? (Kant, 1996, p. 34). Esse dilema pedagógico, enfatizado por Kant, é atualmente revitalizado de forma contundente, sobretudo na chamada cultura digital, pois na sociedade em que tudo parece ser permitido, a realização do desejo parece não mais deparar-se com quaisquer obstáculos e todas as informações passam a ser acessíveis, bastando o clicar de um mouse, os educadores tendem a reagir violentamente ao perceberem que sua autoridade é cada vez mais questionada pelos alunos - os mesmos que, em muitas ocasiões, controlam os recursos tecnológicos com muito mais desenvoltura que os próprios professores.

Porém, é justamente nessa sociedade que a figura do professor precisa ser ressignificada. Não há mais espaço para o exercício do autoritarismo docente, ao qual o mestre se aferra para poder ser identificado como o proprietário da primeira e da última palavra do debate pedagógico. Ao criticar a uniformização e a padronização hegemônicas do pensamento, tanto dentro como fora das instituições escolares, Pedro afirmou que

a homogeneização dos gostos e dos modos de vida não se reflete necessariamente numa vida política e social ou em formas de comportamento consensuais. Em meio à dissolução dos ideais 
políticos e dos projetos de transformação social, persistem os conflitos e contradições alimentando o sonho de um mundo diferente desse que vivemos. Penso que vale a pena apostar nessa contracultura fazendo dela um projeto de liberdade e autonomia (GOERGEN, 2011, p. 126).

Essa manifestação de esperança se torna plausível também por meio da atitude do educador que verdadeiramente ouve o que seus alunos estão dizendo, a ponto de poder reformular certezas que, a princípio, pareciam ser irredutíveis. O exemplo de vida de Pedro Goergen como educador lembra muito a definição de professor elaborada por Jean Pierre Vernant (2002, p. 32): "É preciso começar por deixar de ser professor para poder sê-lo". Justamente porque deixou de ser professor, no sentido de aferrar-se à soberba intelectual, e preferiu humanisticamente elogiar o processo argumentativo, Pedro Goergen sempre foi e sempre será um grande educador, para a alegria daqueles que tiveram e têm o privilégio de com ele conviver.

\section{Referências}

ADORNO, Th. W. Tabus a respeito do professor. Trad. Newton Ramos de Oliveira. In: ZUIN, A., PUCCI, B.; RAMOS-DE-OLIVEIRA, N. Adorno: o poder educativo do pensamento crítico. 5.ed. Petrópolis, RJ: Vozes, 2012.

BOURDIEU, P. Contrafogo: táticas para enfrentar a invasão neoliberal. Trad. Lucy Magalhães. Rio de Janeiro: Jorge Zahar, 1998.

CAMBI, F. História da pedagogia. Trad. Álvaro Lorencini. São Paulo: ed. UNESP, 1999.

COSTA, Belarmino César G., Estética da Violência, Jornalismo e Produção de Sentidos. Campinas, SP: Autores Associados; Piracicaba, SP: ed. Unimep, 2002.

\begin{tabular}{c}
\hline Filosofia e Educação [RFE] - Volume 8, Número 2- Campinas, SP \\
Junho-Setembro de 2016 - ISSN 1984-9605 - p. 62-78
\end{tabular}


COMÊNIO, J. A. Didactica Magna. Lisboa: Calouste Gulbenkian. Trad. Joaquim Ferreira Gomes, 1985.

FREUD, S. "Algumas reflexões sobre a psicologia escolar". In: Edição eletrônica brasileira das obras completas de Sigmund Freud, v. XIII (1913-1914). Rio de Janeiro: Imago, 1969.

GOERGEN, P. Educação para a responsabilidade social: pontos de partida para uma nova ética. In: SEVERINO, Francisca Eleodora Santos (org.). Ética e formação de professores: política, responsabilidade e autoridade em questão. São Paulo: Cortez, 2011.

HERBART, J. F. Pedagogia geral. Trad. Ludwig Scheidl. Lisboa: Calouste Gulbenkian, 2003.

KANT, I. Sobre a pedagogia. Trad. Francisco Cock Fontanella. Piracicaba, SP: ed. Unimep, 1996.

LEGRAS, B. Violence ou douceur. Les normes éducatives dans les sociétés grecque et romaine. In: VERGER, Jacques. Historie de L'education. Paris: Institut National de Recherche Pédagogique, n. 118, Avril-Juin, p. 11-35, 2008.

MANACORDA, M. A. História da educação: da antiguidade aos nossos dias. Trad. Gaetano Lo Mônaco. São Paulo: Cortez; Autores Associados, 1989.

MENCHEN, D. Aluna é suspensa após postar lições no Facebook. In: Folha de São Paulo. Caderno Ribeirão, p. 11, 14/06/2011.

ROUSSEAU, J-J. Emílio ou da educação. Trad. Sérgio Milliet. Rio de Janeiro: Bertrand Brasil, 1992.

TÜRCKE, C. Sociedade excitada: filosofia da sensação. Trad. Antônio Zuin, Fabio Durão, Francisco Fontanella e Mario Frungillo. Campinas: ed. Unicamp, 2010.

VERNANT, J. P. Entre mito e política. Tradução de Cristina Murachco. São Paulo: Edusp, 2002.

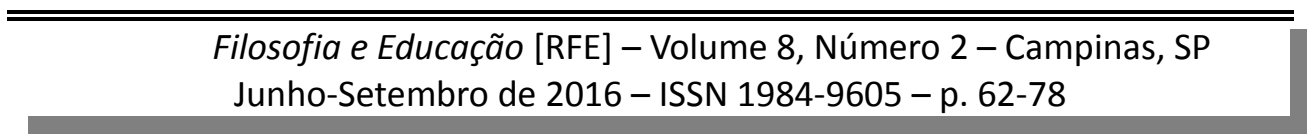


ZUIN, Antonio A. S. Indústria Cultural e Educação - O Novo Canto da Sereia. Campinas: Autores Associados, 1999. 